\title{
Computational Approach to Image Segmentation Analysis
}

\author{
Gourav \\ CGC-COE/CSE, Mohali, Punjab,India \\ Email: Chalotragourav@gmail.com \\ Tejpal Sharma and Harsmeet Singh \\ CGC-COE/CSE, Mohali,Punjab,India \\ Email: tejpal.coecse@cgc.edu.in,Er.harsmeet@gmail.com
}

\begin{abstract}
Image division refers to the way toward dividing an advanced picture into various portions. Image division says to a parcel of an image into various divisions that are homogeneous or comparable. The objective of the division is to Simplify or potentially changes the portrayal of an image into something that is more important and simpler to dissect. Advancement of precise image division different image division strategies is utilized to take care of a particular issue. The motivation behind this survey is to give an overview of various image division methods. These methods are sorted into four sorts: an) Edge based division b) Threshold Segmentation c) Clustering-based division D) Region-based division. This survey tended to different image division methods, their correlation and presents the issues identified with those procedures.
\end{abstract}

Index Terms-Image processing, Image division, Segmentation methods.

\section{INTRODUCTION}

One of the real objectives of image processing is to recover required data from the given picture in a way that it won't impacts alternate elements of that picture. Image Segmentation is one of the principle ventures of picture handling, in which any picture is being subdivided into various sections. Each fragment will speak to some sort of data to the client as shading, force, or surface. Subsequently, it is essential to disconnect the limits of any picture as its portions. De-noising of an image is the most critical stride required to satisfy this necessity [1]. A division is a way of isolating an advanced picture into various areas which have comparative properties, for example, dim level, shading, surface, shine and so forth. On the premise of pixel power, we can separate the limits of various items. Division recognizes isolate protest inside a picture and furthermore discover limit between various locales. Division can be characterized into two sorts: neighborhood division and worldwide division. The nearby division is little windows on an entire picture and manages sectioning sub-picture. The worldwide division manages sectioning entire picture. Worldwide division generally manages moderately substantial no of a pixel.
Be that as it may, neighborhood division manages to bring down no of the pixel as a contrast with the worldwide division. Subsequent to expelling noise from a picture, you can play out any operation in that picture. The significance of Image division can't be ignored in light of the fact that it is utilized as a part of practically every field of science, i.e., expelling commotion from a picture, therapeutic pictures, satellite imaging, machine vision, PC vision and military, Image Retrieval extricating highlights and perceiving objects from the given picture. Picture division is one of the established issues in picture handling and PC vision. Utilizing of Image segmentation we can ready to comprehend the principal of advanced picture preparing. Picture division is utilized to the improvement of the picture and furthermore valuable to the various therapeutic application. Image segmentation can likewise use for examination of the picture and further pre-preparing of the picture. After a division procedure, each period of picture treated in an unexpected way. Presently we are experiencing about medicinal pictures like Ultrasound Images (US) which is broadly utilized today The term image division alludes to the parcel of a picture into an arrangement of locales that cover it[2]. The objective in many assignments is for the districts to speak to significant ranges of the picture, for example, the products, urban regions, and woodlands of a satellite picture. In different examination assignments, the districts may be sets of fringe pixels gathered into such structures as line fragments and roundabout bend sections in an image of 3D modern articles. Locales may likewise be de-noising require as gatherings of pixels having both a fringe and a specific shape, for example, a circle or oval or polygon. The region of image segmentation can be identified by:

- Regions of an image division ought to be uniform and homogeneous regarding some trademark, for example, dark level, shading, or surface

- Region insides ought to be straightforward and without numerous little gaps.

This procedure of division will dole out a solitary incentive to every pixel of a picture with a specific end 
goal to make it simple to separate between various locales of any picture. This separation between various fragments of the picture is done on the premise of three properties of the picture, i.e. shading, power, and surface of that picture. Thusly the determination of any picture division strategy is done subsequent to watching the issue area. Picture division is the way toward relegating a name to each pixel in a picture to such an extent that pixels with a similar name share certain qualities [3]. The after effect of picture division is an arrangement of fragments that aggregately cover the whole picture or an arrangement of shapes separated from the picture. Each of the pixels in a locale is comparative concerning some trademark or figured property, for example, shading force or surface. Contiguous districts are fundamentally unique regarding a similar trademark. At the point when connected to a heap of pictures, regular in therapeutic imaging the subsequent shapes after picture division can be utilized to make $3 \mathrm{D}$ recreations with the assistance of addition calculations like walking 3D squares.

\section{IMAge Segmentation Methods}

Image segmentation is to segment a picture into critical areas. Picture division is an essential stride in image examination, object identification, Feature extraction, representation, visualization and numerous different pictures preparing undertakings Segmentation is the most critical part in picture handling. Fence off a whole picture into a few sections which is something more important and less demanding for further process. Image segmentation calculations depend on either intermittent guideline or likeness rule [4]. The aim behind the brokenness standard is to concentrate districts that contrast in properties, for example, force, shading, surface, or some other picture measurements. The goal behind the closeness rule is to gathering pixels in light of basic property. Some important methods of image segmentation are described below in figure 1 .

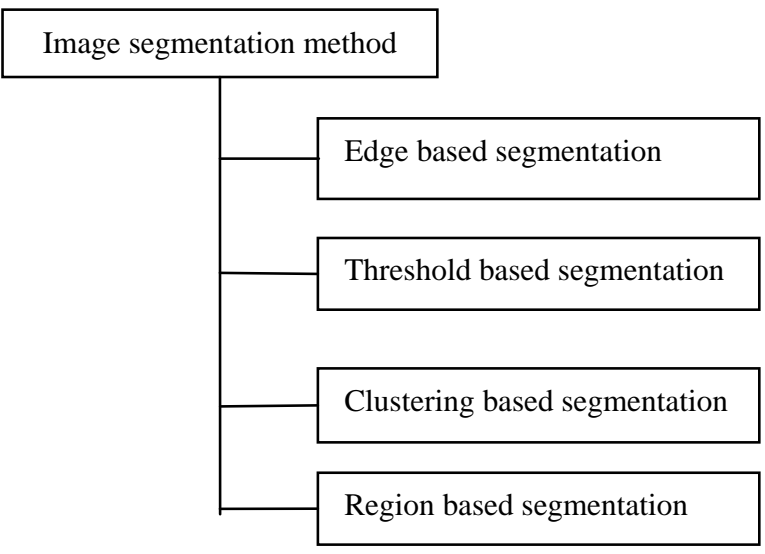

Fig.1. Image Segmentation methods [3], [4].

On different components that are contained in the picture. It might be either color or texture. Before denoising a picture, it is divided to recuperate the first picture [3]. The primary aphorism of the division is to diminish the data for simple examination. The division is additionally valuable in Image Analysis and Image Compression.

\section{A) Egde Based Segmentation}

Edge detection is more typical for identifying discontinuities in gray level than distinguishing disconnected focuses and thin lines in light of the fact that confined focuses and thin lines so not happen as often as possible in most viable pictures. The edge is the limit between two locales with generally particular dim level properties. It is accepted here that the move between two locales can be properties. And the move between two locales can be resolved on the premise of dim level discontinuities alone. In this edge based division, there is no requirement for the distinguished edges to be shut [4]. There are different edge indicators that are utilized to fragment the picture.

\section{a) Edge detection techniques}

There are many edge detection procedures in the writing for image division. The most usually utilized discontinuity based edge identification procedures are checked on in this segment. Those strategies are Roberts' edge location, Prewitt administrator, Sobel edge identification. [5].

1) Roberts cross operator: The Robert Cross administrator plays out a straightforward and fast 2-D spatial slope estimation on a picture. The administrator comprises of a couple of $2 \times 2$ convolution bit as appeared in figure two. These portions are intended to react maximally to edges running pixel grid one bit for each of the two opposite introductions. The portions can be connected independently to the information picture to create isolated Measurement of the inclination segment in every introduction these can then be joined together to locate the supreme extent of the slope at each point. [6].

\begin{tabular}{|l|l|}
\hline 1 & 0 \\
\hline 0 & -1 \\
\hline \multicolumn{3}{|c|}{$\mathrm{Gx}$} \\
\hline 1 & 0 \\
\hline 0 & -1 \\
\hline
\end{tabular}

Fig.2. Roberts's operator 2 × 2 masks [6]

2) Prewitt Operator: The Prewitt edge detector is thought to be the applicable approach to computing the extent and introduction of a picture. Prewitt is equivalently like Sobel administrator and is generally used to distinguish the vertical and level edges of a picture. The fundamental thought behind edge discovery is to discover puts in a picture where the force changes rapidly [6], [7]. The Prewitt administrator comprises of match of $3 \times 3$ convolution parts that are given Figure 4 . 


\begin{tabular}{|c|c|c|}
\hline-1 & 0 & +1 \\
\hline-1 & 0 & +1 \\
\hline-1 & 0 & +1 \\
\hline \multicolumn{3}{|c|}{ Gx } \\
\hline+1 & +1 & +1 \\
\hline 0 & 0 & 0 \\
\hline-1 & -1 & -1 \\
\hline
\end{tabular}

Fig.3. Prewitt operator's $3 \times 3$ masks [7].

3) Sobel Edge Detection: Sobel operator is one if the pixel based edge recognition calculation. It can distinguish edge by computing halfway subordinates in 3 $\mathrm{x} 3$ neighborhoods. The explanation behind utilizing Sobel operator is that it is heartless to noise and it has generally little veil in pictures. These kernels are intended to react to edges running vertically and on a level plane with respect to the pixel framework, one piece for each of the two opposite introductions. The bit is connected are connected exclusively to the info picture so as to create the inclination segment in separate introduction $\mathrm{Gx}$ and Gy [8].

\begin{tabular}{|l|l|l|}
\hline-1 & 0 & +1 \\
\hline-2 & 0 & +2 \\
\hline-1 & 0 & +1 \\
\hline \multicolumn{3}{|c|}{$\mathrm{GX}$} \\
\hline
\end{tabular}

\begin{tabular}{|c|c|c|}
\hline+1 & +2 & +1 \\
\hline 0 & 0 & 0 \\
\hline-1 & -2 & -1 \\
\hline \multicolumn{3}{|c|}{ Gy } \\
\hline
\end{tabular}

Fig.4. Sobel operator's 3 x 3 mask [8].

\section{B) Threshold Based Segmentation}

Threshold is the least difficult approach to performing division, and it is utilized broadly in many image handling applications. The threshold depends on the thought that areas relating to various locales can be arranged by utilizing a range work connected to the force estimations of image pixels. The assumption is that diverse region in an image will have an unmistakable recurrence appropriation and can be discriminated on the premise of the mean and standard deviation of every circulation. [9].
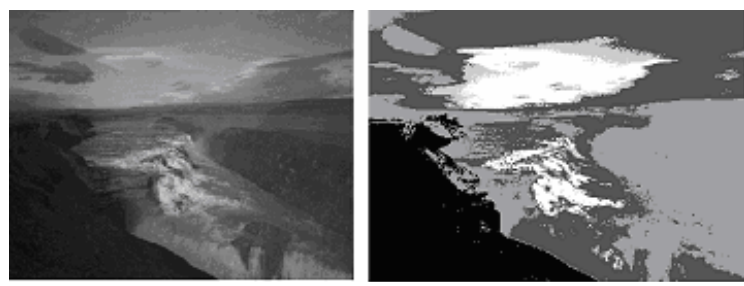

Fig.5. Examples of gray level threshold based segmentation [13], [14]
Threshold techniques are one of the important techniques in image segmentation. This technique can be expressed as

$$
T=T[x, y, P(x, y), f(x, y)]
$$

Where $\mathrm{x}$ and $\mathrm{y}$ are the pixels, $\mathrm{P}(\mathrm{x}, \mathrm{y}), \mathrm{f}(\mathrm{x}, \mathrm{y})$ are the points of the gray level image. The threshold is divided into two types:-

1. Global Threshold: This is finished by utilizing any suitable edge esteem. This estimation of $\mathrm{T}$ will be steady for an entire picture [16]. On the premise of $\mathrm{T}$ the yield picture $\mathrm{q}(\mathrm{x}, \mathrm{y})$ can be acquired from unique picture as $\mathrm{P}(\mathrm{x}$, $\mathrm{y})$.

2. Variable Threshold: In variable threshold, the value of $\mathrm{T}$ can vary over the image [10].

\section{* Methods of thresholding:}

a) Basic threshold: Basic threshold limit is finished by going by every pixel site in the picture, and set the pixel to greatest esteem if its esteem is above or equivalent to a given edge esteem and to the base esteem if the edge esteem is beneath the pixels esteem actualized by the capacity edge in edge [16].

b) Band threshold: Band threshold is like fundamental edge, yet has two edge values, and set the pixel site to greatest esteem if the pixels force esteem is between or at the edge values, else it set to least.

c) P-tile threshold: P-tile is a technique for picking the edge an incentive to contribution to the "fundamental limit" calculation. P-tile signifies "Percentile", and the limit is been the power esteem where the total entirety of pixel powers is nearest to the percentile. Executed by the capacity p-tile Threshold in the edge.

d)Adaptive threshold: Adaptive threshold figures out how to get the borders of the shapes somewhat more right, additionally creates somewhat more garbage and a parameter that chooses what number of patches the picture is isolated into along every hub.

e) Optimal threshold: optimal threshold chooses an edge esteem that is actually ideal, in light of the substance of the picture [11].

\section{C) Clustering Based Segmentation}

In cluster based segmentation, information is joined into gatherings to such an extent that the information with comparable components will fall in one gathering while the information groups are being not the same as each other. The k-mean clustering is regularly utilized for deciding the association of the information. Clustering is the undertaking of collection an arrangement of articles such that items in a similar gathering are more comparative .This unsupervised bunching approach has a solid proclivity to get caught into nearby minimal while creating an ideal arrangement and subsequently it makes grouping completely reliant on the essential group focuses appropriation [12]. 


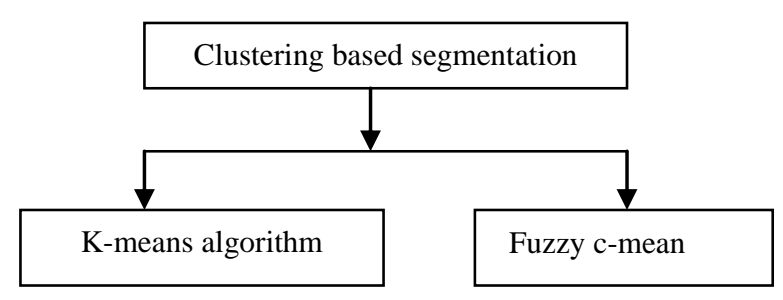

Fig.7. Types of clustering based segmentation [14]

\section{1) K-means algorithm}

In this algorithm number of craved groups should be chosen at first. K-means algorithm limits the aggregate separation between information focuses and group focus. Steps required in $\mathrm{k}-$ means algorithm are:

- Decide a number of desired clusters k, randomly set the $\mathrm{k}$ - group focuses on various beginning areas in the picture.

- Assign every pixel to the bunch having focus closest to that particular pixel [15].

- Compute new bunch focus, which ought to be normal co-ordinates of information focuses.

- Repeat the procedure until no more changes are required.

\section{2) Fuzzy C-means Clustering Method (FCM)}

Fuzzy C - means method proposed by Y. Yang is an iterative clustering method for color image segmentation. In this method pixel can belong to more than one cluster and set of membership level is associated with each pixel. FCM requires cluster center along with objective function FCM generates fuzzy partition matrix.

\section{D) Region-Based Segmentation}

The essential motivation behind district Region based segmentation system the comparative subset or pixels of a picture in light of a few criteria is assembled together to shape picture locale. Image locales are star grouping of associated pixels with comparable assets. So Region is a picture comprises of a gathering of pixels having comparative properties. This technique is straightforward and more insusceptible to noise [17]. Edge based system to segment a picture into a locale that is a unique arrangement of predefined criteria. In district based division areas are built by a partner or separating neighbor pixels. It chips away at the rule of homogeneity, by considering the way that neighboring pixels inside area groups comparable qualities and unlike the pixels in different locales. In the event that the outcome is certain then that specific pixel is added to the pixel to develop developing is to fragment a whole picture $\mathrm{R}$ into littler sub-pictures [18].

\section{a) Region based segmentation methods}

A region meant by $\mathrm{R}$ of a picture is clarified as an associated homogenous subset of an image viewing some rule, for example, dark level or surface. Districts in an image are a gathering of associated pixels with comparative properties. In the area approach [19], every pixel is appointed to a specific protest or locale. Districtbased division likewise requires the utilization of fitting thresholding procedures. The critical standards are helpfulness likeness (which have dark esteem contrasts and dim esteem difference) and spatial vicinity (which comprises of Euclidean separation and smallness of a region).Segmentation calculations in view of district predominantly incorporate strategies.

\section{Region Growing}

Region developing is capacity for evacuating a locale of the picture that is associated in light of some predefined criteria. This standard depends on force data. District developing is a way to deal with an image segmentation in which neighboring pixels are analyzed and joined to a locale class of no edges are identified. Area developing methodology is the inverse of the split and unions approach [20]:

a) An underlying arrangement of little territories is interactively converged by similitude requirements.

b) Start by picking a self-assertive seed pixel and contrast it and neighboring pixels.

c) The region is developed from the seed pixel by including neighboring pixels that are comparative, expanding the span of the area.

d) When the development of one district stops we essentially pick another seed pixel which does not yet have a place with any area and begin once more.

e) This entire process is preceded until all pixels have a place with some area [21].

\section{Region Splitting and Merging}

a) The fundamental thought of district part is to break the picture into an arrangement of disjoint locales, which are intelligent inside themselves:

b) Initially, take the picture in general to be the region of intrigue.

c) Look at the range of intrigue and choose if all pixels contained in the district fulfill some similitude imperatives.

d) If TRUE then the range of intrigue compares to a whole locale in the picture.

e) If FALSE split the zone of intrigue (more often than not into four equivalent subareas) and consider each of the sub-regions as the zone of enthusiasm for a turn.

f) This procedure proceeds until no further part happens. In the most pessimistic scenario, this happens when the ranges are only one pixel in size [22].

\section{RELATED WORK}

The principle motivation behind the segmentation procedure is to get more data in the locale of enthusiasm for a picture which helps in explanation of the questioning scene. Image segmentation goes for space free segment of the picture into an arrangement of 
outwardly unmistakable and homogeneous areas regarding certain properties. Many picture division strategies have been produced by specialists and researchers utilized as a part of picture division are appeared beneath in tab. A survey table for related work of image segmentation methods is given below.

Table 1. Survey tables of various image segmentation methods (2011 to 2017).

\begin{tabular}{|c|c|c|c|c|}
\hline Ref & Year & Segmentation type & Method/algorithm & Features \\
\hline$[26]$ & 2011 & $\begin{array}{ll}\text { Edge } & \text { detection } \\
\text { techniques } & \end{array}$ & $\begin{array}{l}\text { Roberts edge detector, Sobel } \\
\text { Edge Detector, Prewitt edge } \\
\text { detector }\end{array}$ & $\begin{array}{l}\text { A perfect edge delineates extricating the primary edge } \\
\text { elements of an image. }\end{array}$ \\
\hline [27] & 2012 & $\begin{array}{l}\text { Grayscale } \quad \text { image } \\
\text { segmentation }\end{array}$ & Histogram thresholding & $\begin{array}{l}\text { Histogram thresholding is proposed with a specific end } \\
\text { goal to help the division venture in what was observed to } \\
\text { be powerful. }\end{array}$ \\
\hline$[32]$ & 2014 & $\begin{array}{ll}\text { Supervised } & \text { Semantic } \\
\text { Segmentation } & \end{array}$ & $\begin{array}{l}\text { Novel conditional random field } \\
\text { (CRF) }\end{array}$ & $\begin{array}{l}\text { A novel contingent irregular field (CRF) based structure } \\
\text { for the feebly administered semantic division }\end{array}$ \\
\hline$[30]$ & 2015 & Firefly segmentation & k-mean algorithm & $\begin{array}{l}\text { Uses k-mean algorithm and firefly to cluster image pixels } \\
\text { into k cluster for segmentation. }\end{array}$ \\
\hline$[38]$ & 2015 & $\begin{array}{ll}\text { Noisy } & \text { Image } \\
\text { Segmentation } & \end{array}$ & Using PSO and Fuzzy C-Means & $\begin{array}{l}\text { Molecule Swarm Optimization (PSO) is utilized to } \\
\text { adaptively look for edge values that create the best } \\
\text { division comes about at the point when connected in the } \\
\text { wavelet shrinkage. }\end{array}$ \\
\hline [37] & 2015 & $\begin{array}{l}\text { Fuzzy Multi-Region } \\
\text { Technique }\end{array}$ & $\begin{array}{l}\text { Generation of Optimal Random } \\
\text { Fields for Image Segmentation }\end{array}$ & Utilized for ideal mean an incentive for the clustering. \\
\hline [39] & 2015 & $\begin{array}{ll}\text { Cartoon } & \text { Image } \\
\text { Segmentation } & \end{array}$ & $\begin{array}{l}\text { SLIC Superpixels and Adaptive } \\
\text { Region Propagation merging }\end{array}$ & $\begin{array}{l}\text { To enhance the nature of the superpixels era in light of } \\
\text { the network imperative. }\end{array}$ \\
\hline [33] & 2016 & $\begin{array}{l}\text { Brain Segmentation In } \\
\text { MR Image }\end{array}$ & Otsu's threshold method & $\begin{array}{l}\text { Used to arrange regions dually distinguished as would be } \\
\text { expected cerebrum tissue in T1-weighted pictures and } \\
\text { injury districts in } \mathrm{T} 2 \text {-weighted pictures. }\end{array}$ \\
\hline$[28]$ & 2016 & $\begin{array}{l}\text { Otsu's Image } \\
\text { Thresholding Technique }\end{array}$ & $\begin{array}{l}\text { The iterative } \\
\text { thresholding technique }\end{array}$ & $\begin{array}{l}\text { Otsu's thresholding technique with ordinary mind tissue } \\
\text { removed from T1-weighted MR pictures, and injury } \\
\text { locales extricated from T2-weighted MR pictures. }\end{array}$ \\
\hline [29] & 2016 & $\begin{array}{l}\text { Biomedical Image } \\
\text { segmentation }\end{array}$ & $\begin{array}{l}\text { Automated } \\
\text { algorithms }\end{array}$ & Give an overview of current picture division techniques. \\
\hline [36] & 2016 & $\begin{array}{l}\text { Novel Natural Image } \\
\text { Segmentation Algorithm }\end{array}$ & $\begin{array}{lll}\text { Fuzzy } & \text { C-Means } & \text { Clustering } \\
\text { Method } & & \end{array}$ & Gives better division. \\
\hline$[48]$ & 2016 & $\begin{array}{l}\text { Semi-automated } \\
\text { vertebral segmentation }\end{array}$ & 12-APR and ROI method. & Proposed strategy is for human spine vertebra. \\
\hline [34] & 2016 & $\begin{array}{l}\text { Parallel Spatial-Domain } \\
\text { Liver Segmentation }\end{array}$ & $\begin{array}{l}\text { Liver Segmentation of CT } \\
\text { Abdominal Images }\end{array}$ & $\begin{array}{l}\text { the parallel calculation is planned and executed on GPU } \\
\text { for enhancing the calculation effectiveness of the spatial } \\
\text { area. }\end{array}$ \\
\hline [45] & 2016 & $\begin{array}{ll}\text { Medical } & \text { Image } \\
\text { Segmentation } & \end{array}$ & $\begin{array}{l}\text { FCM And } \\
\text { Level Set Algorithm }\end{array}$ & $\begin{array}{l}\text { FCM and Level Set calculation for picture division is } \\
\text { possible and has an extraordinary impact }\end{array}$ \\
\hline$[44]$ & 2016 & $\begin{array}{l}\text { Segmentation } \\
\text { Textured Images }\end{array}$ & Hierarchical Gibbs Model & $\begin{array}{l}\text { Show the execution of the created calculation with cases } \\
\text { of modeled and genuine finished pictures preparing. }\end{array}$ \\
\hline [43] & 2016 & $\begin{array}{l}\text { Spatially Compact } \\
\text { Mixture Model }\end{array}$ & EM algorithm & $\begin{array}{l}\text { Builds up a quick EM calculation. Tests utilizing } \\
\text { engineered and regular pictures are introduced to } \\
\text { demonstrate the adequacy of the proposed algorithm. }\end{array}$ \\
\hline$[42]$ & 2016 & $\begin{array}{l}\text { Automated segmentation } \\
\text { of media-adventitia }\end{array}$ & $\begin{array}{l}\text { A non-parametric thresholding } \\
\text { algorithm }\end{array}$ & $\begin{array}{l}\text { Customary incorporated procedures. In light of arithmetic } \\
\text { morphology and raised body method are connected to } \\
\text { gauge limits of lumen and media-adventitia. }\end{array}$ \\
\hline [41] & 2016 & $\begin{array}{l}\text { Auto Associative Neural } \\
\text { Network segmentation }\end{array}$ & mapping a domain of images & $\begin{array}{l}\text { Broadly utilized as a part of models of counterfeit neural } \\
\text { systems and were joined by the model. }\end{array}$ \\
\hline [40] & 2016 & $\begin{array}{l}\text { Background } \quad \text { Image } \\
\text { Segmentation }\end{array}$ & $\begin{array}{l}\text { Run-Length-encoding (RLE) and } \\
\text { the foreground is encoded via } \\
\text { Lempel-Ziv-77 (LZ77) method }\end{array}$ & $\begin{array}{l}\text { Foundation and forefront of the picture are isolated with } \\
\text { an edge ascertained through recognizing foundation } \\
\text { pinnacle of picture dim histogram. }\end{array}$ \\
\hline$[31]$ & 2017 & $\begin{array}{ll}\text { Medical } & \text { Image } \\
\text { Segmentation } & \end{array}$ & Local Edge Features & $\begin{array}{l}\text { A level set advancement that depends on the } \\
\text { minimization of target vitality useful whose vitality terms } \\
\text { are weighted as indicated by their relative significance in } \\
\text { identifying limits. }\end{array}$ \\
\hline
\end{tabular}




\section{CRITICAL ANALYSIS}

This study additionally gave a basic examination of image division techniques and indicated which strategy is more fitting to be utilized as a part of which circumstance. Picture division is regularly used to find articles and limits (lines, bends, and so forth.) in pictures. All the more correctly, picture division is the way toward relegating a mark to each pixel in a picture to such an extent that pixels with a similar name share certain qualities. After the investigation of all picture division methodologies, it found that grouping based procedure is the best approach for picture division. Clustering is the undertaking of collection an arrangement of articles such that items in a similar gathering are more comparative. It can be accomplished by different calculations that vary essentially in their idea of what constitutes a bunch and how to effectively discover them. Cluster examination, all things considered, is not a program errand, but rather an iterative procedure of learning disclosure or intelligent multi-target improvement that includes trial and disappointment. It is regularly important to adjust information preprocessing and demonstrate parameters until the outcome accomplishes the coveted properties. A basic investigation of different division systems described below table 2 .

Table 2. Comparison of image segmentation techniques [43], [34], [23]

\begin{tabular}{|c|c|c|c|c|c|}
\hline S.No & Segmentation method & Method overview & Merits & Demerits & applications \\
\hline 1 & Edge- based segmentation & $\begin{array}{l}\text { In view of intermittent } \\
\text { of pixels or pixels } \\
\text { having } \\
\text { forces. }\end{array}$ & $\begin{array}{l}\text { Effectively discovery } \\
\text { of the edges }\end{array}$ & $\begin{array}{l}\text { This strategy is less } \\
\text { safe to the commotion } \\
\text { and not works if the } \\
\text { edges are not } \\
\text { characterized } \\
\text { flawlessly. }\end{array}$ & $\begin{array}{l}\text { Medical imaging, face } \\
\text { detection }\end{array}$ \\
\hline 2 & Threshold-based segmentation & $\begin{array}{l}\text { Relies on upon the } \\
\text { histogram of a picture. }\end{array}$ & $\begin{array}{l}\text { A basic approach in } \\
\text { which there is no any } \\
\text { prerequisite of earlier } \\
\text { learning of picture. }\end{array}$ & $\begin{array}{l}\text { It doesn't function } \\
\text { admirably if an } \\
\text { excessive number of } \\
\text { edges are available or } \\
\text { not fit for level valleys. }\end{array}$ & $\begin{array}{l}\text { Medical imaging, } \\
\text { Locate tumors }\end{array}$ \\
\hline 3 & Region- based segmentation & $\begin{array}{l}\text { Gathering of pixels } \\
\text { having comparative } \\
\text { properties and shape } \\
\text { the district }\end{array}$ & $\begin{array}{l}\text { Function admirably } \\
\text { when the locale } \\
\text { homogeneity criteria } \\
\text { are effortlessly } \\
\text { characterized and } \\
\text { more resistant to } \\
\text { noise. }\end{array}$ & $\begin{array}{l}\text { This strategy comprises } \\
\text { of double division } \\
\text { which requires some } \\
\text { serious energy and } \\
\text { memory }\end{array}$ & $\begin{array}{ll}\text { Neural network } & \text { edge } \\
\text { pattern and } & \text { Pixel } \\
\text { aggregation } & \end{array}$ \\
\hline 4 & Clustering- based segmentation & $\begin{array}{l}\text { Gathering the pixels } \\
\text { having comparative } \\
\text { properties. }\end{array}$ & $\begin{array}{l}\text { Effectively discovery } \\
\text { and execution. }\end{array}$ & $\begin{array}{l}\text { Requirements to } \\
\text { characterize the } \\
\text { estimation of clustering } \\
\text { i.e. K }\end{array}$ & $\begin{array}{l}\text { Measure tissue } \\
\text { Volumes. }\end{array}$ \\
\hline
\end{tabular}

\section{CONCLUSION}

Image segmentation is the division of an image into regions or categories which correspond to various objects. This is commonly used to distinguish objects or other applicable data. In this survey, a brief study on different segmentation techniques has been given. Most common methods for image segmentation are: a) edge based segmentation b) Threshold based segmentation c) Clustering-based segmentation d) Region-based segmentation. After the analysis of various methods of picture division, it is found that a clustering based segmentation is the best approach for image division. Clustering based segmentation is done by utilizing FCM (fuzzy c-mean) and K-mean algorithm which is superior to other strategies. This survey provides a brief overview of image segmentation methods and related work done in the field of image division.

\section{ACKNOWLEDGEMENT}

Authors would like to express his thanks to all the anonymous reviewers who have suggested the valuable comments to improve this paper. We also thank Tejpal Sharma from Chandigarh group of college for their assistance and advice on the English expression in this document and advice for MATLAB programming.

\section{REFERENCES}

[1] Y. Saraf, “Algorithms for Image Segmentation," p. 30, 2006.

[2] Z. Cebeci and F. Yildiz, "Comparison of K-Means and Fuzzy C-Means Algorithms on Different Cluster Structures," J. Agric. Informatics, vol. 6, no. 3, pp. 13-23, 2015.

[3] R. R. and K. Tejaswini, "A Survey of Image Segmentation Algorithms Based On Fuzzy Clustering," Int. J. Comput. Sci. Mob. Comput., vol. 2, no. July, pp. 200-206, 2013.

[4] R. Maini and H. Aggarwal, "Study and comparison of various image edge detection techniques," Int. J. Image Process., vol. 3, no. 1, pp. 1-11, 2009.

[5] K. K. Singh and A. Singh, "A study of image segmentation algorithms for different types of images," Int. J. Comput. Sci., vol. 7, no. 5, pp. 414-417, 2010.

[6] U. G. Nevagi, "Edge Detection Techniques: A Survey," vol. 5, no. 2, pp. 274-281, 2016.

[7] P. Kamavisdar, S. Saluja, and S. Agrawal, "A survey on image classification approaches and techniques," Int. J. $A d v$. ..., vol. 2, no. 1, pp. 1005-1009, 2013.

[8] C. Science and M. Studies, "A Survey on Image Segmentation Techniques and Clustering," vol. 7782, no. 
December, pp. 45-51, 2013.

[9] D. Kaur and Y. Kaur, "Various Image Segmentation Techniques: A Review," Int. J. Comput. Sci. Mob. Comput., vol. 3, no. 5, p. 809-814, date accessed: 18/05/2016, 2014.

[10] N. Tokas, S. Karkra, and M. K. Pandey, "Comparison of Digital Image Segmentation Techniques- A Research Review," vol. 5, no. 5, pp. 215-220, 2016.

[11] R. Yogamangalam and B. Karthikeyan, "Segmentation Techniques Comparison in Image Processing," vol. 5, no. 1, pp. 307-313, 2013.

[12] W. Khan, "Image Segmentation Techniques: A Survey," J. Image Graph., vol. 1, no. 4, pp. 166-170, 2013.

[13] A. K. Chaubey, "Comparison of The Local and Global Thresholding Methods in Image Segmentation," no. 1, pp. $1-4,2016$.

[14] C. Pantofaru and M. Hebert, "A Comparison of Image Segmentation Algorithms," Robotics, vol. 2, no. CMU-RITR-05-40, pp. 123-130, 2005.

[15] C. P. M. H. Cmu-ri-tr- and C. P. M. H. Cmu-ri-tr-, "A Comparison of Image Segmentation Algorithms," Robotics, p. 336, 2005.

[16] P. Malji and S. Sakhare, "Survey on Methodologies and Techniques Involved in Feature Selection," vol. 4, no. 3, pp. 275-280, 2016

[17] "a Survey of Various," pp. 273-279, 2015.

[18] A. Manikannan and J. Senthilmurugan, "A Comparative Study about Region Based and Model Based Using Segmentation .Techniques," pp. 1948-1950, 2015.

[19] N. M. Zaitoun and M. J. Aqel, "Survey on Image Segmentation Techniques," Procedia Comput. Sci., vol. 65, no. Iccmit, pp. 797-806, 2015.

[20] K. Camilus and V. Govindan, "A review on graph based segmentation," Int. J. Image, vol. 4, no. 4, pp. 3194-3197, 2012.

[21] R. Dass and S. Devi, "Image Segmentation Techniques," Int. J. Electron. Commun. Technol., vol. 3, no. 1, pp. 6670, 2012.

[22] S. Saini and K. Arora, "A Study Analysis on the Different Image Segmentation,” Int. J. Inf. Comput. Technol., vol. 4 , no. 14, pp. 1445-1452, 2014.

[23] A. Kauri and P. Kaur, "A Comparative Review of Various Segmentation Techniques for Early Detection of Exudates in Retinal Fundus Images," pp. 1-4, 2016.

[24] E. P. Thakur and E. N. Madaan, "a Survey of Image Segmentation Techniques," Int. J. Res. Comput. Appl. Robot. www.ijrcar.com, vol. 24, no. 4, pp. 158-165, 2014.

[25] S. Chen and H. Leung, "Chaotic spread spectrum watermarking for remote sensing images," J. Electron. Imaging, vol. 13, no. 1, p. 220, 2004.

[26] S. S. Al-Amri, N. V. Kalyankar, and S. D. Khamitkar., "Image segmentation by using edge detection," Int. J. Comput. Sci. Eng., vol. 2, no. 3, pp. 804-807, 2010.

[27] P. D. Raju and G. Neelima, "Image Segmentation by using Histogram Thresholding," Ijcset, vol. 2, no. 1, pp. 776-779, 2012.

[28] P. S. N. Holambe and P. G. Kumbhar, "Comparison between Otsu' s Image Thresholding Technique and Iterative Triclass," vol. 33, no. 2, 2016.

[29] C. Science, W. B. Mikhael, and C. Science, "Overview of current Biomedical Image segmentation methods," pp. 803-808, 2016.

[30] A. Sharma, "Image Segmentation using Firefly Algorithm," 2016.

[31] A. Khadidos, V. Sanchez, C. Li, and S. Member, "Weighted Level Set Evolution Based on Local Edge Features for Medical Image Segmentation," vol. 7149, no. c, 2017.

[32] Y. Li, Y. Guo, Y. Kao, and R. He, "Image Piece Learning for Weakly Supervised Semantic Segmentation,” pp. 1-12, 2016.

[33] S. Lu and L. Lei, "A Hybrid Extraction-Classification Method For Brain Segmentation In MR Image," pp. 1381-1385, 2016.

[34] X. Yang, C. Guo, and A. S. S. Method, "Parallel SpatialDomain Liver Segmentation of CT Abdominal Images."

[35] D. R. I. Xpdq, S. Phwkrg, J. Wkh, K. Dffxudf, and S. L. Q. Vhfwlrq, "6hpl dxwrpdwhg 9huwheudo 6hjphqwdwlrq ri +xpdq 6slqh lq 05, ,pdjhv," pp. 14-16, 2016.

[36] Z. Wang and A. F. C. M. F. Field, "A Novel Natural Image Segmentation Algorithm based on Markov Random Field and Improved Fuzzy C-Means Clustering Method," no. 1.

[37] R. Pemula, "Segmentation using Fuzzy Multi-Region Technique."

[38] S. Mirghasemi, P. Andreae, M. Zhang, and R. Rayudu, "Severely Noisy Image Segmentation via Wavelet Shrinkage Using PSO and Fuzzy C-Means," 2016.

[39] H. Wu, Y. Wu, and S. Zhang, "Cartoon Image Segmentation Based on Improved SLIC Superpixels and Adaptive Region Propagation Merging,” pp. 277-281, 2016.

[40] L. Chen and Z. Wang, "Nearly Lossless HDR Images Compression by Background Image Segmentation," pp. 241-246, 2016.

[41] H. Leonardo and B. Jos, "An AutoAssociative Neural Network for Image Segmentation," 2016.

[42] A. Wong-od, A. Rodtook, S. Rasmequan, and K. Chinnasarn, "Automated segmentation of mediaadventitia and lumen from intravascular ultrasound images using non-parametric thresholding," pp. 220-225, 2017.

[43] Y. Linsen, L. Yanjun, C. Deyun, and L. Peng, "A Spatially Compact Mixture Model for Image Segmentation,” pp. 470-473, 2016.

[44] V. N. Vasyukov and A. Y. Zaitseva, "Segmentation of Textured Images Described by Hierarchical Gibbs Model," pp. 452-455, 2016.

[45] S. Qian and G. Weng, "Medical Image Segmentation Based on FCM And Level Set Algorithm ( I," no. Figure Id, pp. 225-228, 2016

\section{Authors' Profiles}

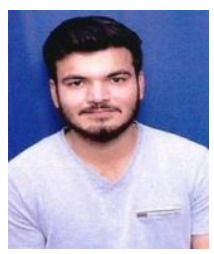

Gourav is currently pursuing M.tech in computer science from CGC-COE, Mohali, Punjab. He received his B.tech degree in computer science from S.S.C.E.T Badhani, Punjab in 2014 and presently working in the area of "Digital image processing" with his Asst. professor Tejpal Sharma.

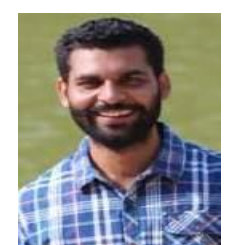

Tejpal Sharma presently pursuing Ph.D. on "digital image processing" from Punjab university, Chandigarh and receive his M.tech degree from B.B.S.B Engineering College, Fatehgarh Sahib, Punjab.Currently working as an Assistant professor in Chandigarh group of College, Landran,

Mohali and Punjab. 
Harsmmet singh is currently pursuing M.tech in computer science from CGC-COE, Mohali, and Punjab. He received his B.tech degree in computer science from Gulzar Group of institute, punjab in 2015.

How to cite this paper: Gourav, Tejpal Sharma, Harsmeet Singh,"Computational Approach to Image Segmentation Analysis", International Journal of Modern Education and Computer Science(IJMECS), Vol.9, No.7, pp.30-37, 2017.DOI: 10.5815/ijmecs.2017.07.04 